\title{
The Comparative Behaviour of Native Oysters (Ostrea edulis) and Portuguese Oysters (Ostrea (Gryphea) angulata) in certain Lethal Solutions of T.N.T. (Trinitrotoluene).
}

\author{
By \\ J. H. Orton, D.Sc., \\ Senior Naturalist at the Plymouth Laboratory. \\ With Analyses by the Government Chemist.
}

With 2 Figures in the Text.

\section{CONTENTS.}

Introduction

Discussion on the comparative physiological condition of Portuguese and native oysters

The material used for the experiments

The T.N.T. used for the experiments

Experiment I

Control to Experiments I and II

Experiment II

Summary and remarks on Experiments I and II $\quad . \quad$. $\quad . \quad$. $\quad .284$

Experiment III in Tank 5

\section{INTRODUCTION.}

Is connection with the cause of the unusual mortality of oysters reported on the oyster beds in the Thames Estuary in 1920 (see Min. Agric. and Fisheries Report, Fishery Investigations II, 6, Nos. 3 and 4, 1923-24, London), it is of interest to compare the simultaneous effects of known solutions of T.N.T. (Trinitrotoluene) in sea-water on both Portuguese and native oysters. In order to obtain some information on this problem the experiments described in the following pages have been carried 
out at the request of the Fisheries Department of the Ministry of Agriculture and Fisheries and with the help of the Government Chemist and his assistants.

\section{The Comparative Physiological Condition of Portuguese and Native Oysters.}

Owing to the difference in habits and constitution presented by the two species to be compared certain difficulties arise - in addition to those incidental to experiments on oysters (see Report l.c., p. 178)—in beginning the experiment with comparable material. The chief physiological differences in the two kinds of oysters are: (1) Portuguese oysters are mainly imported into England and mostly laid between tide marks, and are therefore accustomed to wide variations in temperature, whereas the native oyster lives mainly below low-water mark, and is accustomed to a relatively lower range of temperature. (2) The Portuguese oyster shoots its sexual products, eggs and sperm, directly into the sea, whereas the female functioning native oyster retains its eggs inside the shell, and incubates them there to the fully developed larval stage. In English waters the Portuguese oyster spawns with difficulty in a normal summer, whereas the native spawns naturally. (3) In addition, in the native oyster, a rapid change of sex occurs immediately after an individual spawns as a female; whereas the conditions of sex-change, if any, are not known in the Portuguese oyster.

\section{The Material used for the Experiments.}

In order to reduce the difficulties detailed above to a minimum a mixture of English-grown and a few imported Portuguese oysters were dredged along with native oysters from the beds in the River Blackwater, and kept on the shore in Mersea Creek at dead low-water springs for two months (June 8 to Aug. 6, 1925). From the survivors of these a sample of sixty-seven Portuguese and sixty-two native were sent to Plymouth and kept in the tanks under circulation for six weeks before beginning the experiments (Sept. 21-22) now to be described.

Of the oysters sent to Plymouth one native died on August 18 and one Portuguese on September 18, the rest remaining apparently sound to the beginning of the experiments.

\section{The T.N.T. Used For the Experiments.}

The T.N.T. used for the experiments was obtained from the lump used in the cage experiment in the sea at Whitstable (see O.M.I. Report l.c., p. 81). This block of T.N.T. had been kept in sea-water since 1921, 
but was found by the Government Chemist this year to be practically unchanged T.N.T. It was, however, porous and very sodden with water. Before using it, it was well scrubbed to remove any deposit of altered T.N.T. from the surface, and kept in running tap-water for a period altogether of about twelve hours. It was then split in two halves, which were used for the experiment in Tank 5 ; some fragments were used for experiments in bell-jars and others were analysed at the Government Laboratory.

\section{Experiment $I$.}

Two native (N1 and N2) and four Portuguese oysters (P1 to P4) put in $5000 \mathrm{cc}$. of Channel sea-water in a bell-jar with a good air-jet with fragments* of T.N.T. on September 21st, 5.30 p.m.

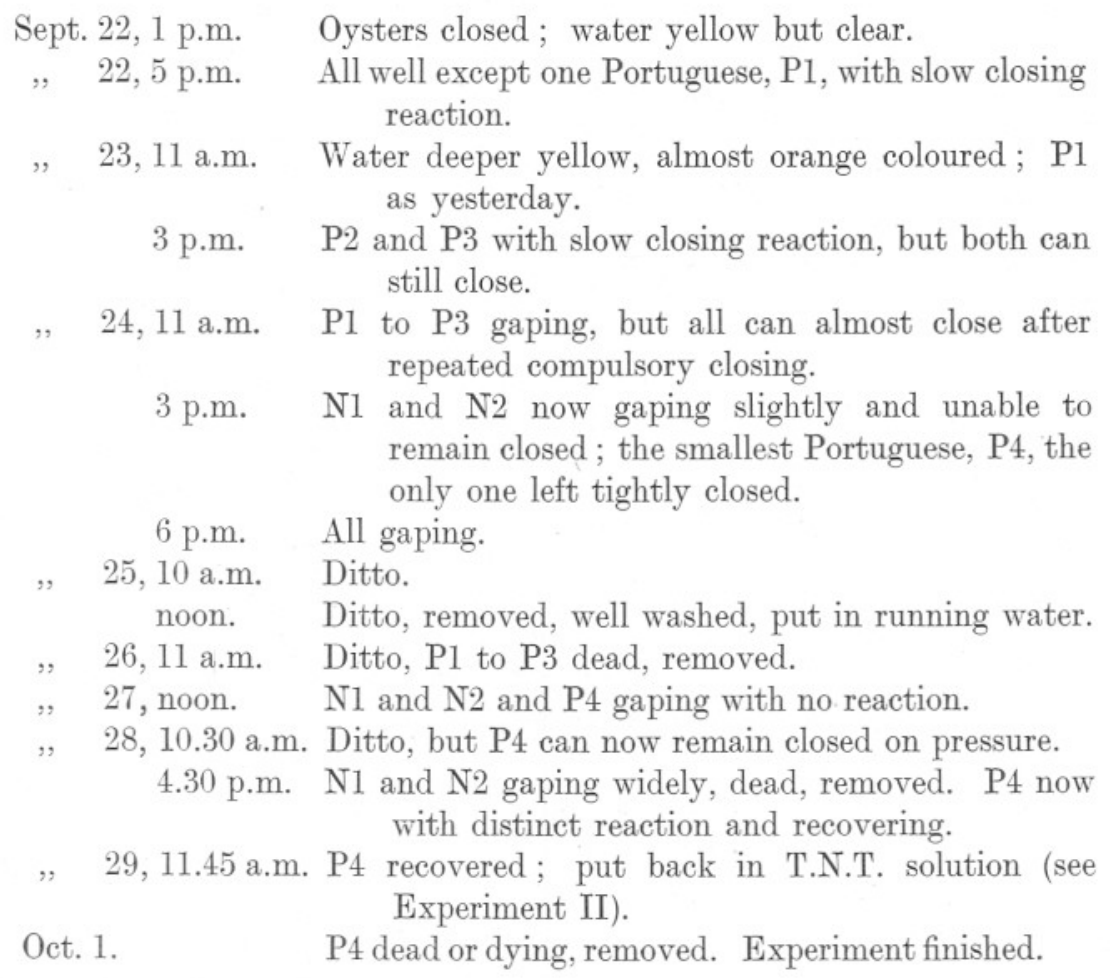

\section{Control to Experiments I and II.}

Similar oysters placed in a bell-jar under the same conditions as in Experiments I and II remained well throughout the period of both experiments. The only point of interest arising out of the control being that on or before September 29th one or more of the Portuguese oysters 
shed a few eggs which did not segment. On October 3 the control oysters were put in Tank 8 .

\section{Experiment II.}

The T.N.T. water from Experiment I was partially decanted and partially filtered into a clean bell-jar, and in it were placed N1 and N2 and P1 and P2 oysters from the control tank (8) on September 25 at 3.45 p.m. with again a good air-jet.

Sept. 26, 11 a.m. $\quad$ N1 gaping with poor reaction; others closed.

, 27, noon. Ditto.

" 28, 10.30 a.m. N1 gaping with slight reaction; N2 closed. P1 gaping and cannot remain closed. $\mathrm{P} 2$ closed.

, 29, 11.45 a.m. N2 and P2 closed. N1 dead, removed. P1 gaping widely, but with a trace of reaction. P4 from Experiment 1 put in this water.

„30, 10.45 a.m. P1 dead, removed. P2 gaping with slight reaction. $\mathrm{N} 2$ and $\mathrm{P} 4$ closed.

Oct. 1. $\quad \mathrm{P} 4$ gaping, removed as dead or dying.

,2. No examination.

, 3. $\mathrm{P} 2$ and $\mathrm{N} 2$ dead, removed. T.N.T. concentration 1 in 140,000 .

Experiment finished.

\section{Summary and Remarks on Experiments I and II.}

The T.N.T. in solution gradually increased in strength in Experiment I to a maximum at the end of the experiment, but the concentration was not determined. The same water was used for Experiment II, and had at the end of that experiment a concentration of 1 in 140,000 (approximately $7 \cdot 1$ parts per million) (see p. 293 , Government Chemist's report).

In Experiment I all the oysters gaped badly in three days, two of the four Portuguese gaping in advance of the natives. The smallest Portuguese survived all the others, recovering after being in the T.N.T. nearly four days, but succumbed afterwards in about one day when put back into the T.N.T. solution.

In Experiment II N1 gaped in one day, P1 on the 3rd, P2 on the 5th, and $\mathrm{N} 2$ on the 6 th or 7 th day. All were dead or dying on the 7 th or 8 th day.

In these experiments no marked difference is observable in the susceptibility to T.N.T. at the concentration used, since first one kind and then the other showed the gaping effect first and last. The widely gaping small Portuguese is interesting in showing that recovery is possible at 
this stage, but a slightly longer period in the T.N.T. would probably have prevented recovery.

The temperature of the water during the experiments was mainly close on $57^{\circ} \mathrm{F}$., the salinity and alkalinity normal or sub-normal; the $\mathrm{pH}$ at the end of Experiment I was courteously determined by Mr. N. .J. Berrill as 7.95 to $8 \cdot 00$.

\section{Experiment III in Tank 5.}

Thirty-one* Portuguese (P1 to P31) and thirty-one* native oysters (N1 to N31) were established in Tank 5; the circulation was cut off on September 22nd, two good air jets added and two lumps of T.N.T. placed alongside the air jets. End of experiment, October 6th.

The results of the experiment are shown in the following table, and in Figs. 1 and 2, p. 286 and p. 287.

\section{TABLE I.}

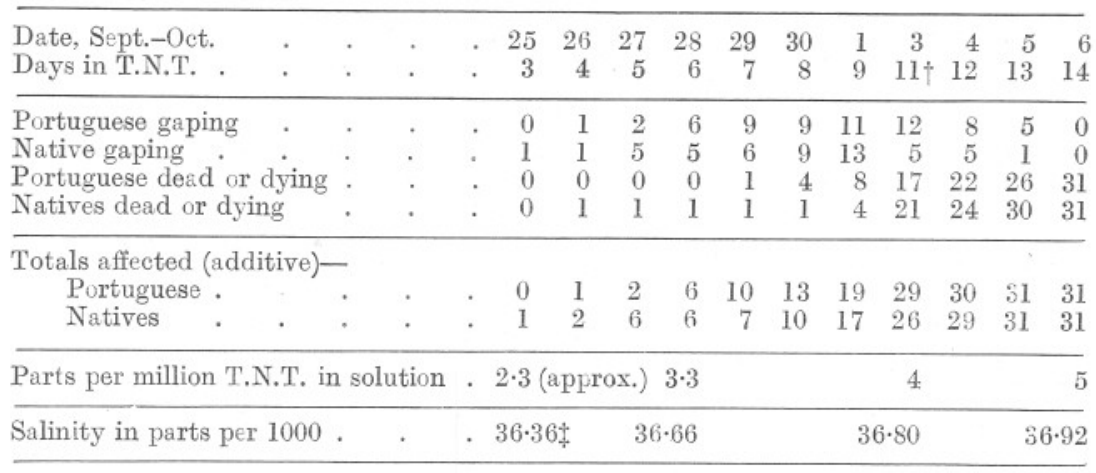

\section{Control to Experiment III (Tank 8).}

In the control experiment in Tank 8 with thirty natives and twentynine Portuguese oysters, begun under exactly similar conditions as held for Tank 5 (except for absence of T.N.T.) there was one death, a native ; the remaining oysters were all well at the end of the experiment andexcept for one Portuguese which died about November 9th-as late as December 12th, as were also two Crepidula, a few anemones, worms, and simple ascidians. The temperature and salinity in Tank 8 varied in almost exactly the same way as in Tank 5 .

\footnotetext{
* One brood Portuguese and one brood native included.

$\uparrow$ On October 3rd when the maximum number of oysters was found gaping or dead, the $\mathrm{pH}$ was found to be 8.00 (courteously determined by Mr. C. F. A. Pantin).

* The salinity of the tank water is ordinarily high, and rose in the experimental tanks (5 and 8) to $36.92 \%$, which is a very high figure and abnormal in our seas.
} 
Fic 1 .

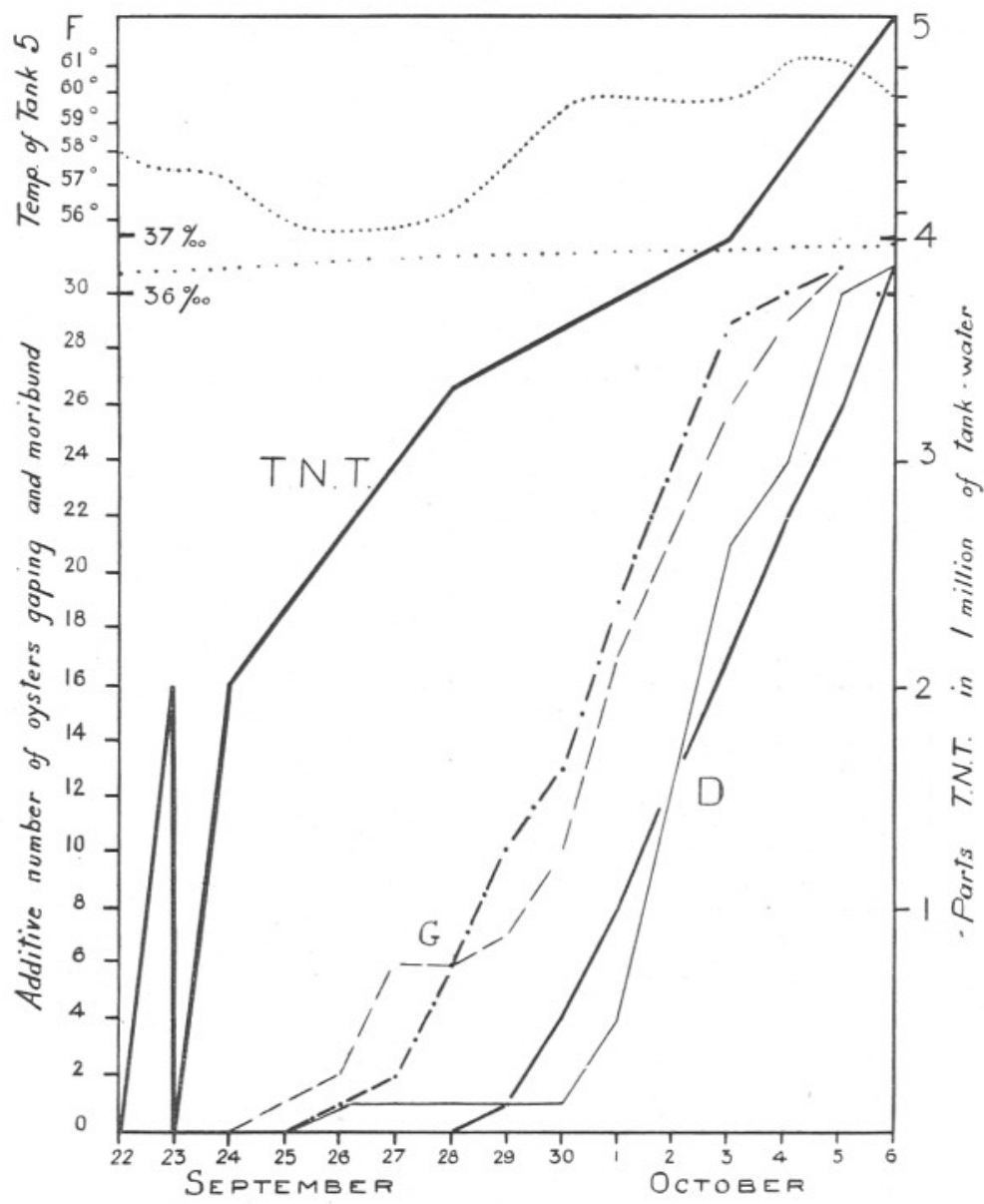

FIG. 1.-Graphs showing the additive numbers of native and Portuguese oysters (G) gaping and (D) dead or moribund, along with the increase in concentration of T.N.T. in Tank 5 and the variation in temperature and salinity.

The thick continuous line with the letters T.N.T. adjacent shows the increase in concentration of the poison.

The discontinuous lines which cross at $\mathrm{G}$ give the additive numbers of oysters gaping on the dates denoted; the thicker line represents Portuguese and the thinner one the native gapers.

The continuous lines which cross at $\mathrm{D}$ give the additive number of oysters taken from the tanks dead or dying; the thicker one again represents the Portuguese and the thinner the native oysters.

The dotted curve gives the temperature variation, and the dotted (almost) straight line the salinity variation. 


\section{Summary of Experiment III.}

A glance at Fig. 1, p. 286, shows that although the earliest oysters to be affected were natives, these did not succumb so soon as the earliest affected Portuguese. Later after about eight days in the T.N.T. the natives began to die rapidly after gaping, but did not on the whole gape so soon as the Portuguese. The lag-period between the first obvious effect of the poison, gaping, and death, was at first longer in the natives than the Portuguese, and afterwards, shorter ; the same lag-period being fairly constant in the Portuguese throughout the experiment.

A glance at Fig. 2, below, shows that the magnitude of the daily rate of gaping alternated in the two species; and that the maximum was first reached by the natives. The daily rate of mortality was at first higher in

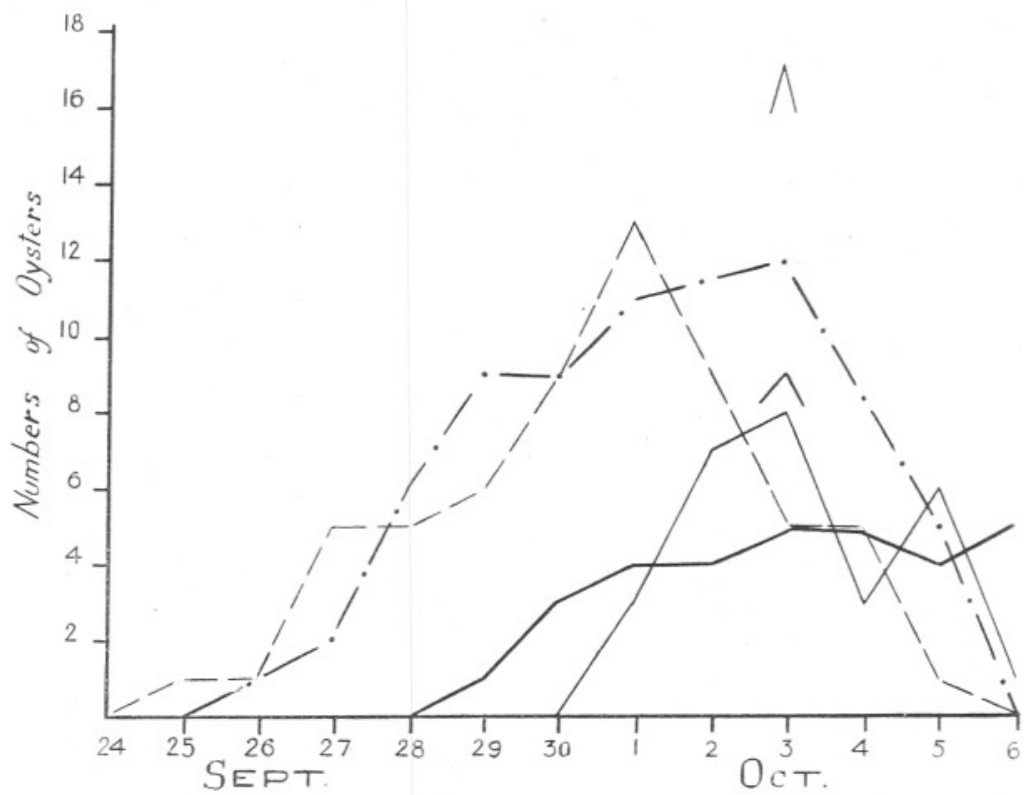

FIG. 2.-Graphs showing the daily number of gaping oysters (discontinuous lines) and daily number of moribund oysters (continuous lines) in Tank 5. The thick lines denote Portuguese oysters and the thin ones natives.

The isolated peaks give the sum of the mortality for the two days,* October lst to 3rd, which is distributed between the 2nd and 3rd October in the main graph to maintain uniformity.

the Portuguese, but a sudden death of a number of natives took the mortality rate of these afterwards to a maximum, after which the rate fluctuated, while that of the Portuguese remained fairly steady to the end of the experiment.

* The tanks could not be examined on Oct. 2 nd.

NEW SERIEs.-Vol. XIV. No. 2. AUgust, 1926. 
Table II shows-by the numbers of the oysters - the order of gaping, while the sequence from above downwards shows the order of death (or moribundity). It is observed that there is a distinct grouping of males amongst the early dying Portuguese and a tendency for the smaller native oysters to group amongst the later dying natives.

Table III gives the history of the oysters from gaping to the condition of being moribund. The recovery of $\mathrm{N} 7$ and longevity of N2, 3, 5, 6 and $\mathrm{F} 1$ and $\mathrm{F} 4$ are remarkable.

\section{TABLE II.}

Showing by the sequence from above downwards the order of death or moribundity in Portuguese oysters (of size and sex shown) and native oysters (size only shown). The serial numbers of both Portuguese and native oysters give the order of gaping. Usually many oysters gaped on one day, as also many died on one day. The length -antero-posterior measurement-, the height-dorso-ventral measurement-and the 1925 approximate growth or shoot measured dorso-ventrally in the median line, are given in millimetres.

$$
\text { Natives. }
$$

Portuguese.

Date. No. Length. Height. 1925 Date. No. Length. Height. 1925 Sex.

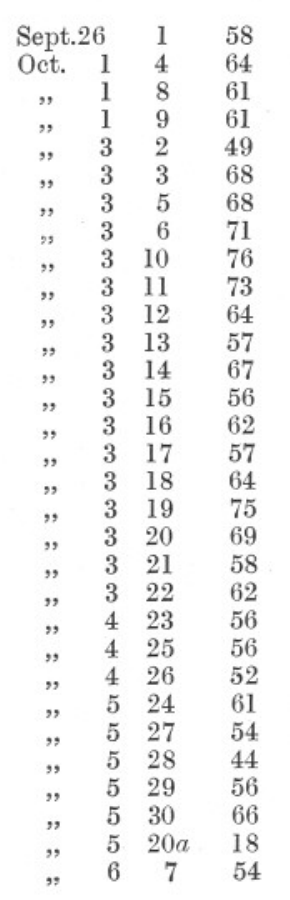

$$
\text { growth. }
$$

\begin{tabular}{|c|c|c|c|c|}
\hline 13 & Sept. & 29 & 2 & 66 \\
\hline 12 & , & 30 & 3 & 56 \\
\hline 8 & , & 30 & 8 & 69 \\
\hline 6 & , & 30 & 10 & 52 \\
\hline 2 ?* & Oct. & 1 & 7 & 50 \\
\hline 8 & , & 1 & 6 & 47 \\
\hline 8 & , & 1 & $6 a$ & 43 \\
\hline 9 & , & 1 & 5 & 57 \\
\hline 10 & ", & 3 & 14 & 47 \\
\hline-22 & ," & 3 & 11 & 57 \\
\hline 12 & , & 3 & 12 & 42 \\
\hline 13 & ", & 3 & 1 & 80 \\
\hline 10 & ," & 3 & 9 & 52 \\
\hline 7 & , & 3 & 13 & 54 \\
\hline 3 & , & 3 & 15 & 59 \\
\hline 7 & , & 3 & 16 & 39 \\
\hline 7 & , & 3 & 19 & 57 \\
\hline 9 & , & 4 & 21 & 51 \\
\hline 8 & , & 4 & 22 & 59 \\
\hline 10 & , & 4 & 25 & 48 \\
\hline 18 & $"$ & 4 & 27 & 54 \\
\hline 14 & , & 4 & 28 & 54 \\
\hline 13 & ," & 5 & 20 & 51 \\
\hline 9 & , & 5 & 23 & 62 \\
\hline 7 & ", & 5 & 24 & 64 \\
\hline $3+?$ & $?$ & 5 & 26 & 44 \\
\hline 8 & , & 6 & 4 & 85 \\
\hline $5+?$ & ? , , & 6 & 17 & 67 \\
\hline 3 & , & 6 & 18 & 51 \\
\hline- & ," & 6 & 29 & 36 \\
\hline 7 & , & 6 & 30 & \\
\hline
\end{tabular}

69
71
66
67
57
57
72
66
77
83
64
58
75
66
60
59
63
87
75
56
65
62
55
54
72
54
50
61
69
23
56
6

\begin{tabular}{|c|c|c|}
\hline & & \\
\hline 85 & 30 & Male. \\
\hline 76 & $?$ & " \\
\hline 91 & $5 ?$ & , \\
\hline 79 & 7 & , \\
\hline 90 & $4-31 ?$ & , \\
\hline 57 & $17\}$ & One male and \\
\hline 56 & $10\}$ & one female. \\
\hline 74 & 5 & Spawning female \\
\hline 103 & 13 & Male. \\
\hline 71 & 17 & Spent female. \\
\hline 82 & 13 & ", \\
\hline 70 & 9-19 & Female. \\
\hline 115 & ? & , \\
\hline 62 & 6 & , \\
\hline 67 & 22 & , \\
\hline 71 & 6 & , \\
\hline 58 & 15 & , \\
\hline 80 & 7 & $"$ \\
\hline 69 & $\begin{array}{l}16 \\
9 .\end{array}$ & $"$ \\
\hline $\begin{array}{l}65 \\
84\end{array}$ & $2 ?$ & , \\
\hline 105 & $9+?$ & , \\
\hline 87 & 5 & ," \\
\hline 103 & 9 & \\
\hline 90 & $5+?$ & ? Male. \\
\hline 86 & 5 & Female. \\
\hline 108 & 14 & ", \\
\hline 76 & 10 & ", \\
\hline 72 & 20 & $"$ \\
\hline $\begin{array}{r}97 \\
112\end{array}$ & $\begin{array}{l}8 \\
7+?\end{array}$ & ", \\
\hline & & $"$ \\
\hline
\end{tabular}
growth.

\section{REMARKs on Experiments I to III.}

Each oyster was numbered on the day of first gaping. Oysters were removed from the experimental vessels when they gaped widely, and showed no reaction when repeatedly forcibly closed; hence although there was no certainty that the oysters removed were actually dead, 


\section{TABLE III.}

History of the Experimental Oysters in Tank 5 with Regard to Gaping and Removal.

\begin{tabular}{|c|c|c|c|c|c|c|c|c|c|c|c|}
\hline Date, Sept. & 25 & 26 & 27 & 28 & 29 & 30 & Oct. 1 & 3 & 4 & 5 & 6 \\
\hline $\begin{array}{l}\text { Serial numbers of } \\
\text { Portuguese Oysters } \\
\text { gaping in the tank } \\
\text { daily at the dates } \\
\text { given above }\end{array}$ & 0 & 1 & $\begin{array}{l}1 \\
2\end{array}$ & $\begin{array}{l}1 \\
2 \\
3 \\
4 \\
5 \\
6\end{array}$ & $\begin{array}{c}1 \\
3 \\
4 \\
5 \\
6 \\
7-10\end{array}$ & $\begin{array}{c}1 \\
4 \\
5 \\
6 \\
7 \\
9 \\
11-13\end{array}$ & $\begin{array}{c}1 \\
4 \\
9 \\
11-18\end{array}$ & $\begin{array}{c}4 \\
17 \\
18 \\
20-28\end{array}$ & $\begin{array}{r}4 \\
17 \\
18 \\
20 \\
23 \\
24 \\
26\end{array}$ & $\begin{array}{r}4 \\
17 \\
18 \\
29 \\
30\end{array}$ & 30 \\
\hline $\begin{array}{l}\text { Portuguese Oysters } \\
\text { removed daily, } \\
\text { dead or moribund } \\
\text { at the dates given }\end{array}$ & & & & & 2 & $\begin{array}{r}3 \\
8 \\
10\end{array}$ & $\begin{array}{l}5 \\
7 \\
6 \\
6 a^{*}\end{array}$ & $\begin{array}{c}1 \\
9 \\
11-16 \\
19\end{array}$ & $\begin{array}{l}21 \\
22 \\
25 \\
27 \\
28\end{array}$ & $\begin{array}{l}20 \\
23 \\
24 \\
26\end{array}$ & $\begin{array}{r}4 \\
17 \\
18 \\
29 \\
\\
30\end{array}$ \\
\hline $\begin{array}{l}\text { Natives gaping in } \\
\text { Tank } 5 \text { daily at } \\
\text { the dates given }\end{array}$ & 1 & 2 & $\begin{array}{l}2 \\
3 \\
4 \\
5 \\
6\end{array}$ & $\begin{array}{l}2 \\
3 \\
4 \\
5 \\
6 \\
7\end{array}$ & $\begin{array}{l}2 \\
3 \\
4 \\
5 \\
6 \\
8\end{array}$ & $\begin{array}{r}2 \\
3 \\
4 \\
5 \\
6 \\
8-10\end{array}$ & $\begin{array}{c}2 \\
3 \\
5 \\
6 \\
10-18\end{array}$ & $\begin{array}{l}23 \\
24 \\
25 \\
26 \\
27\end{array}$ & $\begin{array}{l}21 a \dagger \\
24 \\
27 \\
28 \\
29\end{array}$ & 7 & 7 \\
\hline $\begin{array}{l}\text { Natives removed } \\
\text { moribund at } \\
\text { the dates given }\end{array}$ & & 1 & & & & & $\begin{array}{l}4 \\
8 \\
9\end{array}$ & $\begin{array}{c}2 \\
3 \\
5 \\
6 \\
10-22\end{array}$ & $\begin{array}{l}23 \\
25 \\
26\end{array}$ & $\begin{array}{l}21 a \dagger \\
24 \\
27 \\
28 \\
29 \\
30\end{array}$ & 7 \\
\hline
\end{tabular}

these would certainly be moribund and very near death, if not actually dead. It was necessary to remove oysters at a stage near death, in order to preven unnecessary fouling of the water. To reduce the fouling of the water in the experimental tank, debris was frequently siphoned off and the air jets maintained in good condition; but so long as sickly oysters were present in the tank, it was impossible to ensure water as clean as that in the control. The fact that the water on October $3 \mathrm{rd}$ had a $\mathrm{pH}$ of $8.00 \%$ after the heaviest effect of the T.N.T. on the oysters indicates that the water was maintained in fairly good condition.

The instant at which an oyster gaped in the T.N.T. would depend, among other factors, on how much the bivalve had "tasted " the water. Mitchell has shown (1914)§ that American oysters can remain closed, without taking oxygen, for a week without harm, and Orton \| (1923)

* Brood on No. 6.

I am indebted to Mr. C. F. A. Pantin for this determination.

$\S$ The Oxygen requirements of Shellfish. Bull. U.S. Bureau of Fisheries, XXXII, 1912. (1914).

|| O.M.I. Report loc. cit., p. 64, with full details in MSS. of Report. 
showed that native oysters can live for one to three weeks on a very small quantity of oxygen. Therefore, oysters need not open for upwards of a week for the purpose of taking in oxygen. Nevertheless oysters gaped in Experiment I in from two to four days, and must therefore have taken in T.N.T. water before that time in the act of tasting the water. There may be a difference between native and Portuguese oysters in this respect which might affect the result of the experiments, but it is doubtful if the difference would be great. Experiments on style-formation prove that although the native oyster may not appear to be open, it does mostly taste the water within a period of a few hours from being immersed in it ; and Portuguese oysters probably behave similarly. All the oysters in the experiments therefore probably obtained an early dose of T.N.T., and the more cautious ones would take in at first a smaller dose than the others, and probably be able in this way to delay the acquisition of such a dose as would cause gaping.

Portuguese oysters have, it was found, a slower natural closing reaction than natives, showing that there is a distinct difference in the control of the closing muscles in the two forms. It is possible that the difference in control of the closing muscles is closely correlated with the tendency of Portuguese oysters to lose control of their adductor muscles earlier than natives in T.N.T., and with the experimental observation that when a native gapes in T.N.T. it is nearer death than the Portuguese.

On examining the oysters as they were removed from the experimental tank it was found that all the oysters, except one native and the spawning Portuguese females, were well fished. Generally the tissues of the natives were far more flabby and dead-looking than those of the Portuguese, while the mantle in the natives was mostly well shrunken, though still adhering to the shell, but only about half retracted from the border in the Portuguese. In a few cases, notably N7 and P30, gaping oysters showed a contraction of the heart, if the ventricle were pricked with a needle after removal; but there can be no doubt that such oysters, if not dead, were in the last stages of vitality, and would soon have died if left a little longer in the T.N.T. In the sea, it may be remarked, a widely gaping oyster would have little chance of avoiding death by enemies.

On the morning of September 23rd, the day after the experiment was begun in Tank 5, it was found that one or more male and several female Portuguese oysters had spawned in the water. In this water, which had a concentration of two parts T.N.T. in a million, active sperm was found buzzing around the eggs, which, however, did not segment. The whole of the water in the tank was removed, the oysters and tank well washed and fresh tank water run in to restart the experiment. On the following morning, September 24th, six Portuguese oysters were found to be 
extruding eggs in greater or less quantity (P11 and P12 continued to spawn intermittently for several days), and later four other females shot a portion of their eggs. On this day when the concentration of T.N.T. may be assumed to have been about the same as that on the previous day (about two parts T.N.T. per million), upwards of 5 to $10 \%$ of eggs were found segmenting, and afterwards developed in smaller numbers to a swimming stage, but then died.

The following histories of spawning females are worthy of note as showing that although the slightly spawning females withstood the T.N.T. on the whole, as well as the non-spawners, the two more fully spending females were amongst the first females to die.

\begin{tabular}{ccccl}
$\begin{array}{c}\text { No. of } \\
\text { Oyster. }\end{array}$ & $\begin{array}{c}\text { Date of first } \\
\text { Spawning. }\end{array}$ & $\begin{array}{c}\text { Date of } \\
\text { gaping. }\end{array}$ & $\begin{array}{c}\text { Date } \\
\text { Moribund. }\end{array}$ & \multicolumn{1}{c}{ Remarks. } \\
P5 & 24.9 & 28.9 & 1.10 & Very little spent. \\
P11 & 25.9 & 29.9 & 3.10 & Spent. \\
P12 & 24.9 & 30.9 & 3.10 & Half spent. \\
P20 & 24.9 & $2-3.10$ & 5.10 & Very little spent. \\
P21 & 24.9 & $2-3.10$ & 4.10 & Ditto. \\
P22 & 24.9 & $2-3.10$ & 6.10 & Ditto. \\
P29 & 24.9 & 4.10 & 6.10 & Ditto.
\end{tabular}

The fully and half-spent females, it is to be noted, did not die earlier than most of the males (see Table II). After nine days in the T.N.T. eight Portuguese oysters died, and of these six were males, one a spawning female, and one a ripening female. The physiological condition in relation to sex is therefore an important factor in the experiments. One male lived, however, until the last day but one of the experiment, and was found then to have sperm, which showed mobility in small numbers in Channel water, but none in T.N.T. water.

It would seem that male Portuguese oysters are more susceptible to T.N.T. poison than females, and also that the larger natives gape sooner than the medium-sized ones, but further experiments would be necessary to verify the observation. The last Portuguese to die in Experiment II, it should be noted, was a male.

No Portuguese oysters spawned in the control tank until after the experiment, but a few eggs were discharged by one or more females in the control bell-jar experiment, and none were discharged from four ripe females in Experiment I, and none from two ripe females in Experiment II.

T.N.T. only caused spawning in one experiment, and it is possible that in this case one oyster in Tank 5 was on the point of spawning 
when the T.N.T. was put in the tank, and that either the T.N.T. or the effects of the preparation of the tank, had the effect of making it spawn at once, in the same way as the uncomfortable conditions consequent upon being taken out of water will cause ripe sea-urchins and other marine animals to spawn. The spawning of one individual, especially a male, may very well have started a number of others, male and female, to spawn, as such an occurrence is a not uncommon phenomenon amongst marine animals.*

On the 6th day after putting the T.N.T. in Tank 5 two slipper-limpets (Crepidula fornicata), which were attached to Portuguese oysters, were found detached, and were removed with a third on the following day as dead or dying. Two Crepidula lived in the control tank to date (Dec. 12) in a similar situation.

A few Ascidiella and Ciona (blubber) died in Tank 5 by the 11th day. when similar forms were doing well in Tank 8 . Some small anemones also died in Tank 5, while other similar ones were still alive in Tank 8 on Dec. 12 .

\section{CONCLUSIONS.}

In concentrations of T.N.T. rising rapidly to five to seven parts per million in unchanged sea-water, there is little difference in the susceptibility of the Portuguese and the native oyster to the poison. Subject to confirmation by further experiments - since the early gaping Portuguese were mostly either males or spawning females-it is indicated that Portuguese oysters gape on the average earlier than natives, but do not die so soon after gaping as the natives, especially as the poison becomes more concentrated.

In the same way it is indicated that male and spawning female Portuguese oysters die sooner in T.N.T. than ripening females, and that on the average large native oysters die sooner in T.N.T. than medium-sized natives.

If further information is desired on the comparative effects of T.N.T. on Portuguese and native oysters, it is suggested that more valuable results could be obtained by subjecting the experimental oysters to T.N.T. at a concentration of one to two parts per million in constantly renewed fresh sea-water. In this way a closer approach to the ideal experiment (see O.M.I. Report, p. 179) would be obtained, and the conditions and results would approximate more closely to those which might occur in the sea.

* H. M. Fox, Proc. Camb. Phil. Soc. Biology, I, 2, p. 71, 1924. 
The Government Chemist's Report on the Results of the Examination of Samples of Sea-water for T.N.T. and Salinity.

\author{
(Copy.)
}

Government Laboratory,

Clements' Inn Passage,

Strand, London, W.C. 2.

14th October, 1925.

The T.N.T. was determined by Dr. Brady's method, with certain modifications (see Fishery Investigations II, VI, No. 4, 1924, "An account of Investigations into the cause or causes of the unusual Mortality among Oysters in English Oyster Beds during 1920 and 1921," Part II).

The salinity was determined according to the International Method by Titration against Copenhagen Normal Water.

\begin{tabular}{|c|c|c|c|c|c|}
\hline $\begin{array}{l}\text { Lab. } \\
\text { No. }\end{array}$ & \multicolumn{3}{|c|}{ Particulars of Sample. } & T.N.T. & $\begin{array}{c}\text { Salinity } \\
\text { (parts per } \\
1000) .\end{array}$ \\
\hline 83 & No. 1 , Tank 5 & 23.9 .25 & & 1 in 500,000 & $36 \cdot 38$ \\
\hline 85 & No. $2,,$, & 28.9 .25 & 11 a.m. & 1 in 300,000 & $36 \cdot 66$ \\
\hline 86 & No. 3 & 3.10 .25 & 12.30 p.m. & 1 in 250,000 & $36 \cdot 80$ \\
\hline 88 & No. 4 & 6.10 .25 & 3.30 p.m. & 1 in 200,000 & $36 \cdot 92$ \\
\hline 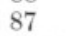 & Experiment II & 3.10 .25 & 12.45 p.m. & 1 in 149,000 & $35 \cdot 50$ \\
\hline 854 & Tank circulation & 22.9 .25 & 4 p.m., temp. & $14 \cdot 4^{\circ} \mathrm{C}$ & $36 \cdot 36$ \\
\hline 855 & Control (to) Experiment II, bell-jar & 3.10 .25 & 1.5 p.m., tem & p. $15 \cdot 5^{\circ} \mathrm{C}$. & $35 \cdot 37$ \\
\hline 856 & Control Tank, 8 & 3.10 .25 & 1.5 p.m., tem & p. $14 \cdot 9^{\circ} \mathrm{C}$. & $36 \cdot 92$ \\
\hline 857 & Tank 8 & 6.10 .25 & 3.30 p.m. & & $36 \cdot 98$ \\
\hline
\end{tabular}

(Sgd.) R. RoBertson,

Government Chemist.

Dr. J. H. ORToN,

Marine Biological Laboratory,

Citadel Hill, Plymouth. 
